\title{
PEST CONTROL ON KIWIFRUIT WITH AN INSECTICIDAL SOAP
}

\author{
A.R. TOMKINS \\ The Horticultural and Food Research Institute of N.Z. Ltd, \\ Ruakura Research Centre, Private Bag 3123, Hamilton
}

\begin{abstract}
Field trials in 1988-89 and 1989-90 evaluated an insecticidal soap alone, with Bacillus thuringiensis (Bt) or an emulsified vegetable oil for pest control on kiwifruit. Insecticidal soap alone or with vegetable oil, reduced fruit damage by caterpillars (13 and 1\%, compared with 41 and $14 \%$ on unsprayed vines). Addition of Bt post-flowering, gave control similar to that of a phosmet programme (both 2\%). Insecticidal soap did not prevent armoured scale insects infesting leaves and fruit, or thrips damaging leaves. Dormant applications of chlorpyrifos with or without phosmet at before flowering improved early season scale control. Thrips control was enhanced by adding vegetable oil. A blemish resembling water staining affected $40 \%$ of the fruit on the vines treated with insecticidal soap alone or with vegetable oil.

Keywords: kiwifruit, insecticidal soap, leafroller, armoured scale insects, phytotoxicity
\end{abstract}

\section{INTRODUCTION}

A rapidly increasing proportion of the New Zealand kiwifruit industry is using a first stage Integrated Pest Management (IPM) system commonly called 'Kiwigreen' (Steven et al. 1994). This system is able to produce fruit with non-detectable pesticide residues at harvest. Insecticides continue to play a significant role in this system, with Bacillus thuringiensis used to control leafrollers and a petroleum oil used against armoured scale insects. There is, however, a need for further insecticides. Insecticidal soaps offer promise because of their low mammalian toxicity and activity against soft scale insects (Singh and Rao 1979), leafhoppers (van Epenhuijsen et al. 1992), thrips (Moore et al. 1979) and mites (Lawson and Weires 1991).

This paper describes trials evaluating two locally developed products, an insecticidal soap and an emulsified vegetable oil used in spray programmes designed to produce nil or minimal pesticide residues on harvested fruit.

\section{METHODS}

Trials were conducted in an orchard near Paeroa on mature kiwifruit vines cv. 'Hayward', which had been unsprayed for at least one season. Randomised block designs were used with six single vine plots (replicates) buffered by unsprayed vines.

The insecticides and their rates ( $\mathrm{g}$ ai/100 litres) were: B. thuringiensis (as $100 \mathrm{~g}$ of Thuricide HP); chlorpyrifos as Lorsban 50WP (25g) (1988-89) or 40EC (24g); phosmet as Imidan 75WP (112.5g); insecticidal soap (Defender) (1 or 2\%) and vegetable oil (Yates Naturoil) (1\%). Spreader/sticker (Citowett at $25 \mathrm{ml} / 100$ litres) was used with phosmet and Thuricide HP (when used alone) in 1988-89 and phosmet (Agral LN at $25 \mathrm{ml} / 100$ litres) in 1989-90. Treatments were applied at a water rate of 2250 litres/ha using a Hardi handgun at $1750 \mathrm{kPa}$ until 30 November 1989, after which it was necessary to use 4667 litres/ha to ensure adequate coverage of the vines due to lack of summer pruning. 
The 1988-89 trial included a calendar programme and two experimental programmes. The former (hereafter called phosmet programme) used a dormant application of chlorpyrifos 50WP, then phosmet full season. Since these trials were conducted the use of phosmet on kiwifruit has been restricted to dormant applications only. Timing followed the export spray programme recommendations current for that season with dormant (12 September); pre-flowering (10 November); early petal-fall (25 November); post-blossom (8 December); 14 days later (22 December 1988) then at 3-4 weekly intervals (11 January, 9 February, 10 March, 13 April 1989). The experimental programmes used insecticidal soap full season with no dormant spray (hereafter called soap), or a dormant application of chlorpyrifos 50WP, then phosmet before flowering followed by Bt plus insecticidal soap for the remainder of the season (hereafter called $\mathrm{OP}+$ soap $+\mathrm{Bt}$ ). In both experimental programmes, insecticidal soap was used at $1 \%$ until February, then at $2 \%$ to assist control of second generation greedy scale. All programmes in 1988-89 used Bt at mid-blossom.

The 1989-90 experimental programme (hereafter called low residue) used two dormant applications of chlorpyrifos 40EC, Bt post-blossom, followed 14 days later by insecticidal soap plus Naturoil (both at 1\%) at fortnightly intervals for the remainder of the season. The pre-flowering insecticide application was omitted as suggested by Blank (1989). The timing of applications was: dormant (12 September and 18 October); post-blossom (30 November); 14 days later (21 December 1989) then at fortnightly or 3-4 weekly intervals (10 and 25 January, 8 and 22 February, 8 and 22 March, 5 and 26 April 1990).

In both trials fruit damage and infestation by insects or mites was determined by randomly sampling 50 fruit per vine on 17 January 1989 and 10 January 1990, and 100 fruit on 11 May 1989 and 10 May 1990. Fruit were cool-stored at $4^{\circ} \mathrm{C}$ until microscopically examined. Scale infestations were monitored by sampling 20 mature leaves at random from the centre of vines at 2-4 weekly intervals. Scale per leaf, species, stage and whether live, dead or parasitised were determined. On 23 November 1988, adult thrips were counted in situ on each of 20 flowers per vine. Infestation and damage by thrips was assessed for leaves sampled on 3 May 1989 and 7 May 1990. Leaf damage was scored by the area affected as severe $\left(>4 \mathrm{~cm}^{2}\right)$, moderate $\left(1-4 \mathrm{~cm}^{2}\right)$, low $\left(<1 \mathrm{~cm}^{2}\right)$ or absent.

Fruit were also assessed for phytotoxic damage. Three types of skin marking were found on fruit sampled on 17 January 1989. These were: fruit with abnormally brown hair bases found either singly (browning) or in groups with the browning connecting hair bases (patches); and toast-coloured areas resembling wind or handling rub (toast). Some fruit harvested on 11 May 1989 were affected by marking resembling the browning/patch marking found earlier except that the colouration was partially red (reddening/browning). The incidence of blemishes resembling water staining were also recorded.

The numbers of insects or mites per 100 fruit were subjected to $\log _{e}(X+1)$ transformation before analysis using ANOVA and percent damage/infestation data were analysed using logit regression analysis.

\section{RESULTS}

In both seasons, fruit damage and infestation by caterpillars tripled between January and May on unsprayed vines (Table 1). Fruit damage and infestation on soaptreated vines was lower although not significantly below that on unsprayed vines. The $\mathrm{OP}+$ soap $+\mathrm{Bt}$ and phosmet programmes gave a similar level of control. A high level of caterpillar control was maintained by the low residue programme throughout the season.

On 17 January 1989, only soap-treated fruit were found to be infested with lepidopterous larvae or pupae i.e. a leafroller larva.Stathmopoda larvae or pupae were found on unsprayed and soap-treated fruit sampled on 11 May 1989, unsprayed and low residue-treated fruit sampled on 10 January 1990 and unsprayed fruit sampled on 10 May 1990. 
TABLE 1: Percent fruit damage and infestation $( \pm \mathrm{SE})$ by lepidopterous larvae or pupae.

\begin{tabular}{lcccc}
\hline \multirow{2}{*}{ Treatment } & \multicolumn{2}{c}{$1988-89$} & \multicolumn{2}{c}{$1989-90$} \\
& 17 Jan. & 11 May & 10 Jan. & 10 May \\
\hline Unsprayed & $12.0(3.5)$ & $41.4(3.8)$ & $4.5(1.4)$ & $13.8(1.4)$ \\
Phosmet & $0.6(0.9)$ & $1.9(1.1)$ & - & - \\
Soap & $7.4(2.1)$ & $13.4(5.1)$ & - & - \\
OP + soap + Bt & $1.9(1.2)$ & $1.6(0.8)$ & - & - \\
Low residue & - & - & $1.4(0.8)$ & $0.8(0.4)$ \\
Significance & $\mathrm{P}<0.001$ & $\mathrm{P}<0.001$ & $\mathrm{P}<0.01$ & $\mathrm{P}<0.001$ \\
\hline
\end{tabular}

Vines were infested with greedy scale (Hemiberlesia rapax) and oleander scale (Aspidiotus nerii). In both seasons greedy scale numbers increased from mid/late January onwards due to the release of second generation crawlers (Figs. 1, 2). Treatments which included dormant applications of chlorpyrifos (phosmet, OP + soap $+\mathrm{Bt}$, low residue) had the lowest levels of leaf infestation when leaf sampling began. The phosmet programme kept leaf infestation at a low level all season whereas infestation rose on vines treated with the $\mathrm{OP}+$ soap $+\mathrm{Bt}$ and low residue programmes. Leaf infestation also increased on vines treated with the soap programme, which included no dormant application, to reach a level similar to that of the unsprayed vines.

In 1988-89 the leaf infestation levels appeared to correspond with those on the fruit better than in the 1989-90 trial (Figs. 1, 2, Table 2) when fruit infestation in the low residue programme was lower than expected from the level of leaf infestation. One dead greedy scale was found on phosmet programme fruit in the 1988-89 trial.
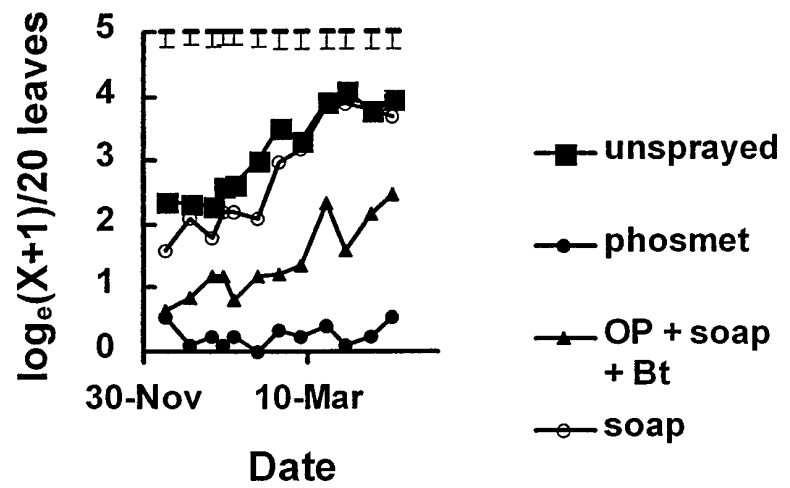

FIGURE 1: Total (live + dead) numbers of greedy scale per 20 kiwifruit leaves at Paeroa in 1988-89 (bars represent SED).

A low proportion of the scale insects on fruit were oleander scale; e.g. 8 and $11 \%$ on unsprayed fruit sampled on 17 May 1989 and 10 May 1990 respectively. On the unsprayed leaves sampled over the entire season, 8 and $3 \%$ of the armoured scale insects were oleander scale in 1988-89 and 1989-90 respectively. On leaves sampled from vines treated with the soap, $\mathrm{OP}+$ soap $+\mathrm{Bt}$ and low residue programmes, 11, 11 and $1 \%$ of the scale insects were oleander scale.

Over the entire season, 38, 50, 21 and $9 \%$ of the third instar greedy scale sampled on unsprayed, phosmet, soap and OP + soap + Bt-treated vines respectively were parasitised. In the following season, 8 and $2 \%$ of the third instar greedy scale were parasitised on unsprayed and low residue-treated leaves. 


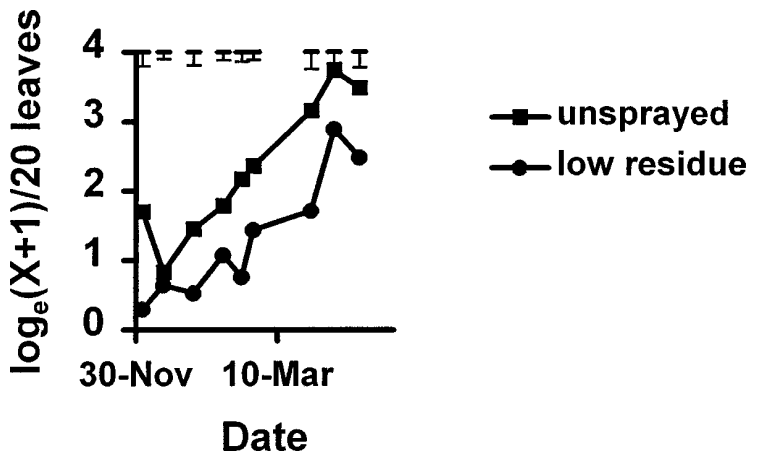

FIGURE 2: Total (live + dead) numbers of greedy scale per 20 kiwifruit leaves at Paeroa in 1989-90 (bars represent SED).

TABLE 2: Percent fruit infestation by scale insects (greedy + oleander pooled) $( \pm$ SE), harvested in May 1989 and 1990.

\begin{tabular}{lcc}
\hline Treatment & 11 May 1989 & 10 May 1990 \\
\hline Unsprayed & $40.6(7.4)$ & 18.0 \\
Phosmet & $0.2(0.7)$ & - \\
Soap & $46.4(14.5)$ & - \\
OP + soap + Bt & $13.8(4.1)$ & - \\
Low residue & - & 2.2 \\
Significance & $\mathrm{P}<0.001$ & $\mathrm{P}<0.01$ \\
\hline
\end{tabular}

None of the 1988-89 spray programmes reduced flower infestation by thrips, which were probably New Zealand flower thrips (Thrips obscuratus) (Table 3). The phosmet programme reduced leaf infestation and damage by thrips (probably greenhouse thrips, Heliothrips haemorrhoidalis), whereas the soap programmes had no effect (Fig. 3). The low residue programme did not reduce thrips damage to leaves eg. 46 and

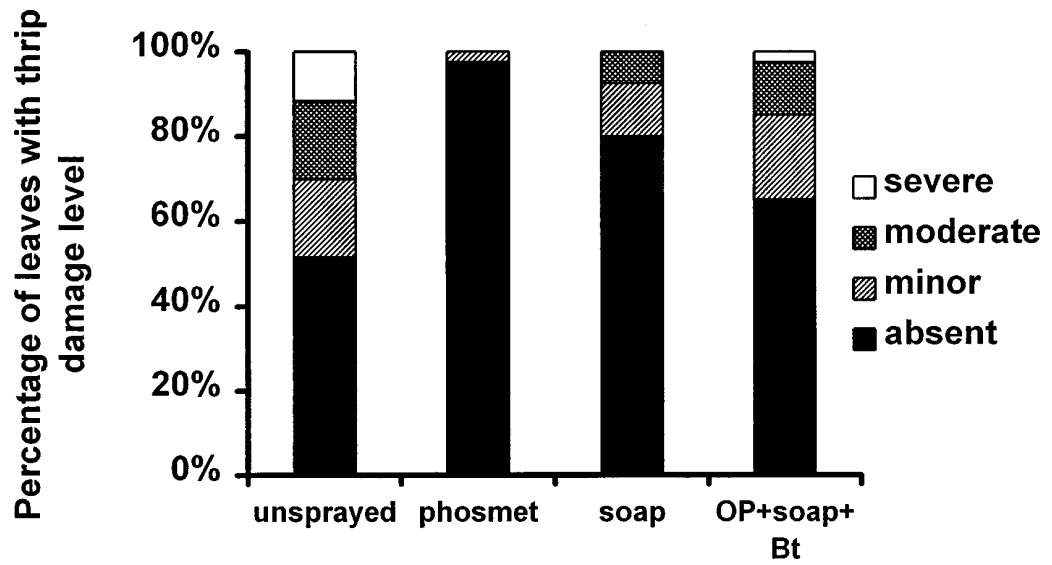

FIGURE 3: Levels of thrips damage to kiwifruit leaves on 3 May 1990. 
$40 \%$ of unsprayed and low residue programme leaves sampled on 7 May 1990 were damaged by thrips.

TABLE 3: Number (after $\log _{\mathrm{e}}(\mathrm{X}+1)$ transformation) of adult thrips on flowers on 23 November 1988, and nymphs and adults on leaves on 3 May 1989 (back-transformed means).

\begin{tabular}{llcl}
\hline Treatment & Per flower & \multicolumn{2}{c}{ Per 20 leaves } \\
& & Nymphs & Adults \\
\hline Unsprayed & $2.4(10.8)$ & $14.3^{1}$ & $0.8(2.2)$ \\
Phosmet & $2.7(15.9)$ & 0.0 & $0.4(1.3)$ \\
Soap & $2.7(15.2)$ & 1.0 & $0.4(1.3)$ \\
OP + soap + Bt & $1.8(13.6)$ & 0.7 & $0.6(1.8)$ \\
SED & 0.25 & - & 0.45 \\
\hline
\end{tabular}

${ }^{1}$ untransformed means

The phosmet and low residue programmes reduced fruit infestation by adult thrips, unlike the soap programmes (Table 4).

TABLE 4: Number (after $\log _{\mathrm{e}}(\mathrm{X}+1)$ transformation) of adult thrips per 100 fruit (back-transformed means).

\begin{tabular}{lll}
\hline Treatment & 11 May 1989 & 10 May 1990 \\
\hline Unsprayed & $2.8(18.0)$ & $1.5(4.9)$ \\
Phosmet & $0.5(1.7)$ & - \\
Soap & $2.0(7.6)$ & - \\
OP + soap + Bt & $1.5(4.6)$ & - \\
Low residue & - & $0.7(2.0)$ \\
SED & 0.45 & 0.40 \\
\hline
\end{tabular}

A low incidence of toast and patch marking was found on fruit sampled on 17 January 1989 with no significant differences between treatments. ie. 0, 0, 1 and 2\% incidence of toast and 1, 5, 0 and $6 \%$ incidence of patch marking on fruit sampled from unsprayed, phosmet, soap and $\mathrm{OP}+$ soap $+\mathrm{Bt}$ vine fruit respectively. The level of increased skin browning was highest on vines treated with soap programmes (Table 5). In January, a similar level of browning was found on both of the programmes using soap. By May the level of browning had declined on the vines treated with the OP + soap + Bt programme, but had risen on the vines treated with the soap programme.

TABLE 5: Percent $( \pm$ SE) of fruit harvested in January and May 1989 with skin marking.

\begin{tabular}{lcccc}
\hline Treatment & \multicolumn{2}{c}{ Browning } & \multicolumn{2}{c}{ Water staining } \\
& 17 Jan. & 11 May 1989 & 11 May 1989 & 10 May 1990 \\
\hline Unsprayed & $1.2(1.3)$ & $3.1(2.1)$ & $3.1(2.4)$ & 1.2 \\
Phosmet & 0.0 & $0.6(0.9)$ & $12.0(4.4)$ & - \\
Soap & $14.6(3.4)$ & $73.2(10.1)$ & $40.2(13.2)$ & - \\
OP + soap + Bt & $18.2(4.2)$ & $9.6(2.9)$ & $6.5(2.8)$ & - \\
Low residue & - & - & - & 79.0 \\
Significance & $\mathrm{P}<0.001$ & $\mathrm{P}<0.001$ & $\mathrm{P}<0.01$ & - \\
\hline
\end{tabular}

${ }^{1}$ represents browning (17 January 1989) and reddening/browning (11 May 1989) marking. 
Whilst sampling low residue-treated vines in April 1990, fruit with a "water stain" blemish were seen. The level and severity of staining was higher than in 1988-89 (Table 5). Whereas the staining affecting the soap-treated fruit often occurred as stripes down the sides of fruit, many low residue programme fruit were almost completely covered in staining. In addition, while the staining in 1988-89 resembled typical water staining, it had a dirty, gritty appearance in the 1989-90 trial. Stained fruit from both trials were treated with citric acid which removed the staining in the 198889 but not in the 1989-90 trial.

\section{CONCLUSIONS}

Although insecticidal soaps have activity against leafroller caterpillars (Smith and Hubbes 1989), the product evaluated in these trials gave inadequate control, possibly due to low residual toxicity (Moore et al. 1979). However, caterpillar control was achieved with $B$. thuringiensis used during and post-flowering in the $\mathrm{OP}+\operatorname{soap}+\mathrm{Bt}$ programme.

Adding one or two dormant sprays of chlorpyrifos to programmes reduced leaf infestation by greedy scale at the start of the season. However, the recovery of greedy scale by the second generation indicates that further control measures were still required. Insecticidal soap used alone or with vegetable oil failed to prevent the recovery and increase in leaf infestation by greedy scale. Fruit infestation was however kept at a low level on vines treated with the low residue programme. The reason for the discrepancy between the relative levels of leaf and fruit infestation on the low residue programme vines is unknown.

Although these trials made some useful progress towards developing spray programmes using insecticidal soap and vegetable oil, further progress was limited by the fruit marking problems. Insecticidal soaps and natural oils are known to be phytotoxic, with plants possessing hairy leaves more prone to phytotoxic damage by soap (Moore et al. 1979). It is therefore possible that the hairy fruit of kiwifruit may be particularly susceptible to marking by soaps.

\section{ACKNOWLEDGEMENTS}

These trials were funded by Yates N.Z. Ltd. Thanks are due to Ms F. Dickson, Mr S. Hutchings, Mr A. Karl, Ms S. Lyons, Mrs L.Ruf, Ms C. Thomson for technical assistance and to Ms. B. Dow for statistical analysis.

\section{REFERENCES}

Blank, R.H., 1989. Is a preblossom spray really necessary? N.Z. Kiwifruit 60: 7.

Lawson, D.S. and Weires, R.W., 1991. Management of European red mite (Acari: Tetranychidae) and several aphid species on apple with petroleum oils and an insecticidal soap. J. Econ. Entomol. 84(5): 1552-1557.

Moore, W.S., Profita, J.C. and Koehler, C.S., 1979. Soaps for home landscape insect control. California Ag. 33(6): 13-14.

Singh, C.P. and Rao, N.S., 1979. Field evaluation of fish oil insecticidal soap against soft green scale, Coccus viridis on citrus. Indian J. Plant Prot. 7(2): 208-210.

Smith, S.M. and Hubbes, M., 1989. Evaluation of the toxicological effects and field efficacy of an insecticidal soap against the spruce budworm (Lepidoptera: Tortricidae). Proc. Ent. Soc. Ontario 119: 53-62.

Steven, D., Tomkins, A.R., Blank, R.H. and Charles, J.G., 1994. A first-stage integrated pest management system for kiwifruit. Proc. Brighton Crop Prot. Conf:: 135-142.

van Epenhuijsen, C.W., Wright, S. and de Silva, H.N., 1992. Evaluation of organic pest control agents. Proc. 45th N.Z. Plant Prot. Conf.: 103-110. 